\title{
Case Report: Locally advanced skin cancer in an albino, a treatment dilemma
}

\section{Mapurisa $\mathbf{G}^{1}$, Masamba $\mathbf{L}^{2}$}

1.College of Medicine, Blantyre

2.Queen Elizabeth Central Hospital, Blantyre

\section{Case Presentation}

We report on a 27 year old albino woman, who was admitted on the 20th May 2010 to our facility at Queen Elizabeth Central Hospital with a left-sided pre-auricular ulcerating mass suspected to be originating from the skin. The mass developed three weeks prior to admission and was progressively growing in size.

Three days before admission she also noticed ulceration and discharge from the wound. There was no associated pain, headache, anorexia, weight loss, night sweats, dizziness, change in hearing or other masses. She had not used any sun protective measures - sun screen agents, hats, sunglasses when outdoors - owing to financial constraints.

\section{Past surgical history}

She had had multiple surgical excisions for squamous cell carcinomatous lesions. The first was seven months prior to this admission: excision of left neck mass invading the sternocleidomastoid muscle as well as a right eyelid tumour. Two months after the first surgical procedure, similar lesions affecting the right cornea, right ear and recurrent right upper eye lid were noticed and excised.

\section{Clinical examination}

The patient was in good 'general performance' status, score 1 according to Eastern Cooperative Oncology Group (ECOG). There were multiple healed post operative scars on the left neck and right face. Vital signs were normal. There was a rounded ulcer in the left pre-auricular area that measured 4 $\mathrm{X} 5 \mathrm{~cm}$, with a necrotic base (Figure 1A).

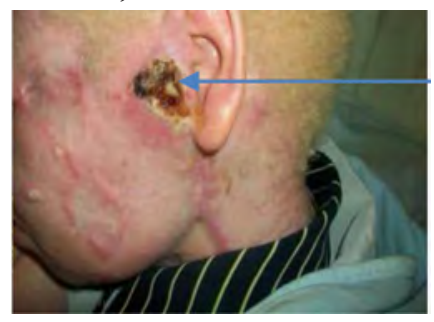

\section{Fig $1 \mathrm{~A}$ Ulcerated mass before chemotherapy}

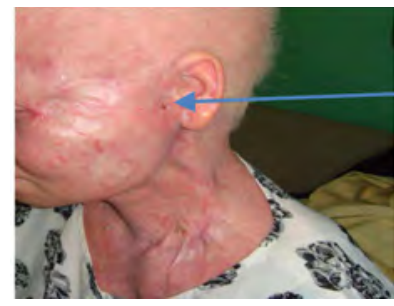

Fig 1B Site of mass after chemotherapy

Base-line blood tests were unremarkable (WCC $=10.3$, $\mathrm{Hb}=10.9, \mathrm{Pl}=459$, creatinine $0.37 \mathrm{mg} / \mathrm{dL})$. Histology of the lesion confirmed cutaneous squamous cell carcinoma.

A chest radiograph was normal. The staging MRI done in May 2010 revealed a hyper-dense infiltrative mass lesion in left temporal area (Figure $2 \mathrm{~A}$ and B) which was extending to full skin thickness and abutting the temporo-mandibular joint and causing an indentation on the outer table of the skull bone. The tumour was finally staged as T4 N0 M0.

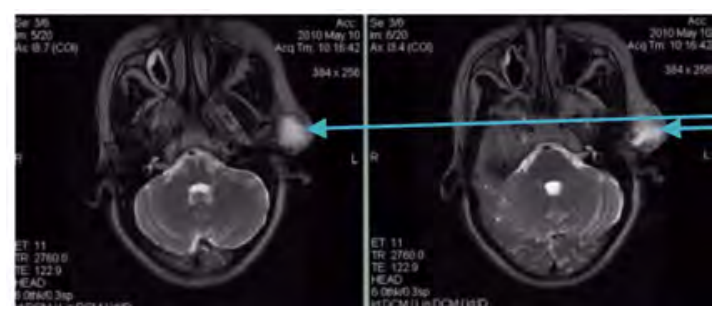

Fig 2A

Fig 2B

Tumor pre-chemotherapy

\section{Treatment}

The tumour was deemed inoperable owing to its extension to the joint and bone. Radiotherapy is not readily accessible to us, so we opted to treat this patient palliatively with chemotherapy using carboplatin $440 \mathrm{mg}$ (calculated at area under the curve 5) and adriamycin $85 \mathrm{mg}$ cycled three-weekly. Following three cycles there was complete clinical response and the skin ulceration healed (Figure1B). A repeat MRI three months after initial imaging showed near complete radiological response (Figure 3).

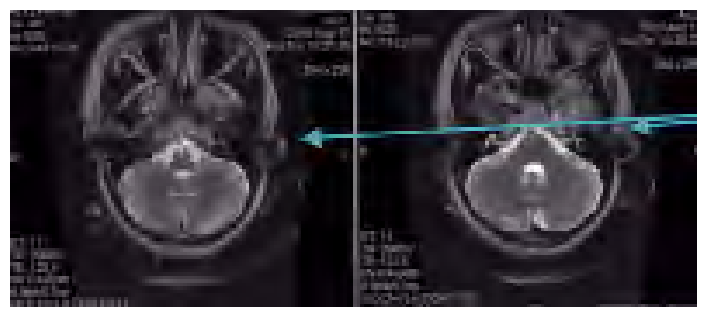

Fig $3 \mathrm{~A}$

Fig 3B

Tumor post-chemotherapy

A total of six cycles of chemotherapy were given (using carboplatin and adriamycin) over a period of fifteen weeks and five days.

\section{Discussion}

Albinism (a genetic disorder of lack of skin pigmentation) has a worldwide distribution ${ }^{1}$. The lack of melanin - a photectic pigment - predisposes albinos to various degrees of actinic injury to the skin, making squamous cell carcinoma the commonest skin malignancy in this population ${ }^{2,3}$. In the African albino the risk of developing this malignancy is up to 1000-fold higher than in the general population ${ }^{4,5}$.

The head and neck is the commonest site for squamous cell cancer. This was the case with our patient, whose five cancerous lesions occurred in this part of her body. Nonuse of protection for the skin further increased the risk of cancer in this patient. In a Nigerian survey of 1000 people with albinism, none was found without malignant or premalignant condition at age above 20 years ${ }^{5}$. This has similarly been reported in Tanzania, where most of the cases are at an advanced stage by the time of presentation. ${ }^{6}$

Radiotherapy, if available, would have been the recommended standard treatment for our patient at the time of her presentation, because of the extent and inoperability of the lesion and because of the likelihood of serious mutilation if surgery were to be performed. Since radiotherapy is not available locally, patients have to go to neighbouring countries 
for such treatment, and the logistical arrangements for this are difficult, expensive and slow. This justified our decision to use chemotherapy in this patient for palliation.

There is no established role of neo-adjuvant chemotherapy in skin cancer. However, following the dramatic clinical response to the first three cycles of chemotherapy in our patient, with complete tumour disappearance, we treated her with an additional three cycles of chemotherapy. Following the complete clinical response shown in Figure1B, we recommended excision 6 weeks post chemotherapy.

\section{Conclusion}

The dramatic response in our patient suggests that chemotherapy may be efficacious as a neo-adjuvant treatment for locally advanced skin cancer in some albino patients. This is a possibility that needs studying in our setting, in which we have no easy access to radiotherapy.

Squamous cell carcinoma of skin was a major problem in our patient. Lack of protective clothing had accelerated the development of this grave complication of her underlying albinism.

\section{Recommendations}

We need more interventional studies in treatment of locally advanced skin cancers in albinos in our setting. Chemotherapy may be tried in such cases if radiotherapy is not possible.

There is need for programmes to assist the albino population in the use of protective clothing against UV light.

\section{References}

1. Yakubu A, Mabogunje OA: Skin cancer in African albinos. Acta Oncol 1993, 32:621-622

2. Kromberg JG, Castle D, Zwane EM, Jenkins T: Albinism and skin cancer in Southern Africa.Clin Genet 1989, 36:43-52.

3. Higgenson J, Oettle AG: Cancer in the South African Bantu. J Natl Cancer Inst 1960, 24:643-647.

4. Iverson U, Iverson OH: Tumours of the skin. In Tumours in a Tropical Country. A survey of Uganda, 1964-68. Edited by: Templeton AC. New York: Springer Verlag; 1973:180-199.

5. Okoro AN: Albinism in Nigeria: A clinical and social study. Br J Dermatol, 1975, 92:485- 492.

6. George Alexander, Ulrich Henschke; Advanced skin cancer in Tanzanian albinos: preliminary observations; Journal of the National Medical Association, 1981, 73:1047-1054

\section{Medical Council of Malawi Continuous Professional Development}

From May 2008 all qualified medical and Dental practitioners are required to obtain $5 \mathrm{O} \mathrm{CPD}$ points in order to renew their licence

\section{PUBLISH AN ARTICLE WITH MALAWI MEDICAL JOURNAL AND OBTAIN 10 POINTS}

Under CPD code C: publications in reference journal as principal or co-author contribute 10 points.

For subscriptions and advertisement please contact the MMJ Office in the Microbiology Building at College of Medicine, Mahatma Gandhi Campus, Blantyre. 